\title{
Interview
}

\section{Exploring the Dialectic: An Interview with James P. Lantolf}

\author{
Deryn P. Verity \\ Associate Editor, JALT Journal
}

\begin{abstract}
T ames Lantolf has become identified with the sociocultural approach to second language acquisition, as developed from the original ideas of Russian psychologist Lev Vygotsky (1896-1934) and others. His Introductory essays in Lantolf and Appel (1994) and Lantolf (2000) are widely cited essential digests of the basic principles and concepts of this theoretical paradigm. Professor Lantolf is Greer Professor in Language Acquisition and Applied Linguistics; Director of the Center for Language Acquisition; and Co-Director of CALPER (Center for Advanced Language Proficiency Education and Research) at Pennsylvania State University. Dr. Lantolf is also the founder of the Sociocultural Theory and Second Language Learning Research Group, which began to meet in 1993. His dozens of publications include three seminal volumes on sociocultural theory: the two collections of articles mentioned above, and a new book, Sociocultural Theory and the Genesis of Second Language Development (2006, coauthor Steven L. Thorne) published by Oxford University Press.
\end{abstract}


JJ: When and how did you begin your shift away from mainstream SLA (second language acquisition) thinking and research?

JPL: My interest in sociocultural theory (SCT) and Vygotsky began about 1983, when I was on the faculty of the University of Delaware. Up to that time in my career, I had no idea who Vygotsky was. At a dissertation defense of one of my students, Bill Frawley, a colleague, asked what I thought was a really interesting question about SLA from an SCT perspective. It immediately piqued my interest, because it represented a viewpoint on SLA that I had never thought of. Bill had been a student of Jim Wertsch at Northwestern University. Jim Wertsch, of course, is one of the individuals most responsible for introducing Vygotsky's ideas to the English-speaking world. Following the defense, Bill and I talked further and then we decided to put together a seminar on SCT where we would read along with our students some of the seminal writings of $\mathrm{Vy}$ gotsky and his colleagues, including Luria, Leontiev, Galperin, et cetera.

JJ: Two of your books are edited collections of SCT-themed papers, one of them coedited with your wife, Gabriela Appel. Your new book was written with a Penn State colleague, Dr. Steven Thorne. Is there a Vygotskyan subtext to these collaborations, a sense that the field needs as many voices to speak for it as possible?

JPL: Collaboration is something that those of us working within SCT have always valued even when we appear to be working alone. This was behind my thinking when we started the SCT and L2 Learning Research Group back in 1993. The idea was to bring together scholars (practicing academics and graduate students) interested in SCT and SLA in a collaborative setting where we would help each other think through our various projects. I didn't think the group would survive more than a year or two, but we just had our 13th meeting at the University of Massachusetts, Amherst, and next year we will meet at the University of Arizona. So, yes, the idea of collaboration, which was at the heart of Vygotsky's own work as he met with his colleagues regularly as they developed their thinking, has become an integral part of the way SCTers do business.

JJ: You have been an advocate for the neo-Vygotskyan paradigm for more than 20 years now. How firmly established do you feel it has become? Does SCT see itself as still being outside the mainstream?

JPL: It depends on which mainstream we are talking about. Within AngloAmerican psychology, the theory is clearly not part of the mainstream. It 
is barely on the radar screen. It is no accident that Mike Cole and Jim Werstch are not in departments of psychology, but in communication and education, respectively. To my knowledge, the only two leading Vygotsky scholars in psychology departments in North America are Jan Valsinser, at Clark University, and Anna Stestenko, at City University of New York.

Within education departments, on the other hand, I believe there is a great deal of interest in Vygotsky's ideas, certainly more than was the case 20 years ago, when Piaget was the dominant figure. Within SLA, SCT has become an accepted part of the research landscape. This is seen in the number of dissertations written in many parts of the world; the number of publications in the leading journals that have an SCT focus; the fact that many of the handbooks in SLA and applied linguistics include a chapter on SCT; and the number of conference presentations, including keynote and plenary addresses, that take an SCT perspective. So, I think the mainstream has widened in general education and in applied linguistics, but psychology, at least the Anglo-American variety, is still not particularly interested in the theory.

JJ: Vygotskyan theory is enjoying what could be called a "boom" here in Japan, but many teachers find it a difficult subject to get a foothold on. Is your new book a good starting point for someone who is new to the theory?

JPL: While the book should be useful for someone new to the theory, it is not a work that one can read through quickly and end with a complete understanding of the theory. I think it will need to be read more than once. But this is because of the nature of the theory itself.

The motivation behind the book is this: while many scholars working in SLA have shown an interest in SCT, they have not, unfortunately, taken the time to read Vygotsky, Luria, Leontiev, and the others who laid the foundation of the theory, as well as important modern scholars such as Wertsch, Michael Cole, and Vera John-Steiner, to name a few. Instead, they have interpreted Vygotsky through the writings that I, and my colleagues, have published in L2 research venues. Consequently, they do not have a full picture of what Vygotsky's theorizing is all about.

As a result, some people have stated in print that Vygotsky's is a sociolinguistic theory, which it most definitely is not, at least not in the standard interpretation of sociolinguistics. Others have claimed that it is a psychological theory that doesn't have a theory of language. To some 
extent this is the case, though if you read Vygotsky closely, you discover that he indeed espouses a theory of language (this is a project that I am currently working on). Others have asserted that, as appealing as the theory is, you still need the metaphor of the "autonomous knower" to account for SLA, because not everything is in the environment (e.g., how do you explain the common assumption of learners that the past tense of eat is *eated instead of ate?). Thus, the thinking goes, you still need cognitive theory [Ed.: a theory that posits cognition being located in the individual mind] to explain SLA.

What people don't understand is that SCT is a cognitive theory-it argues that the source of cognition is social activity. So our 2006 book was written with all of this in mind. We precede each SCT-SLA chapter with a chapter that discusses the relevant theoretical construct in the hopes that this will provide the necessary background for a reader to appreciate what the SLA research is saying.

JJ: If cognition is social, where does that leave concepts such as learner autonomy, self-directed learning, and individual variation?

JPL: Autonomy does not mean autistic. The key point is that individuals are not the starting point but rather the result of development. Human individuals emerge from the dialectical relationship between what is biologically endowed and what is socially / culturally inherited. A physically autonomous entity is still a socially organized and historically constructed individual. Biology provides us with such processes as memory, attention, and consciousness of things around us. This we share with our primate cousins. Culture provides the means through which we come to gain intentional control over our biological endowment. As Vygotsky said, humans, through culture, are able to control rather than be controlled by our brains. This control gives us the ability to inhibit immediate reactions to stimuli from the world, which in turn allows us the option of planning how to respond to the stimuli.

When an animal feels hunger it sets out immediately to seek food. Humans experiencing the same feeling can decide to delay the seeking of food, to build an appropriate weapon, or to coordinate a hunt with other individuals. The capacity to plan symbolically is the primary way we are able to control our biological abilities. Symbols are created by cultures. As Marx put it, the spider builds a web by instinct, while the architect first builds a house symbolically on paper (or on a computer). Among other things, this reduces the risk of getting it wrong when the real building is 
constructed. So, human cognition-understood as the ability to exercise voluntary and intentional control over our biological brains-comes from culture, which creates the symbols that we use to exercise this control.

JJ: I think that many readers here in Japan will be particularly interested in the chapters on SCT-based pedagogies, Dynamic Assessment (DA) and Systemic-Theoretical Instruction (STI). Pedagogy is where a complex theoretical construct like the Zone of Proximal Development (ZPD) makes practical sense.

JPL: I think it is a mistake to turn straight to the pedagogy chapters without a full appreciation of what they are arguing for. The result is likely to be what I have called a "technologization" of the pedagogy, whereby DA or STI is reduced to a set of techniques to follow rather than a completely new approach to understanding the relationship between teacher, learners, and the object of study.

JJ: How do the two teaching methods differ?

JPL: DA and STI illuminate different aspects of the same theory of pedagogy as grounded in Vygotsky's general theory. The most important aspect of STI, which perhaps doesn't come out as forcefully as it should in the book, is that instruction in any field has the responsibility of presenting learners with the very best knowledge on a given object of study available at the time. The object cannot be compromised for the sake of ease of understanding.

On the other hand, pedagogy based on appropriate forms of mediation (DA) must be flexible enough to help learners at any level develop toward full understanding of, and control over, the object of study. Even though we wrote the book only a short while ago, our thinking on STI and DA has changed considerably as a result of carrying out further research and having taught two graduate seminars on these topics. If we were to do a new edition of the book, I think we would integrate STI and DA into a single chapter and show how the two concepts can work more closely in promoting development. [Working papers discussing these pedagogies can be downloaded from the CALPER website: <http:// calper. la.psu.edu>.]

JJ: Your misgivings about concepts being removed from their theoretical context seem well-founded. Many references to SCT concepts in articles and presentations seem deracinated. 
JPL: This is very frustrating. This has been one of the problems we have had to confront almost from the beginning of our efforts. People find various bits and pieces of the theory appealing and then they proceed to work with these bits and pieces independent of the full theory. The classic example is the ZPD, which is perhaps one of the most misunderstood and misused constructs of the entire theory. To extricate the ZPD from Vygotsky's writings on development, mediation, activity, sense, sign, et cetera, undermines the construct itself.

Having said this, I think it is a good thing to extend theoretical constructs and concepts, including the ZPD. Vygotsky himself did not write a lot about the ZPD and after more than 80 years you would think we would have come to a deeper understanding of what the ZPD is about than we have.

However, I don't think this gives one license to interpret the original concept in any way one pleases. To extend, and even to modify, a concept, requires an understanding of what the original notion of the concept was. This, in my view, hasn't happened. What is often passed off as the ZPD (including the notion of scaffolding) is a genuine distortion of how Vygotsky understood development as a mediated process.

JJ: If you were asked to put Vygotsky's main theoretical contribution into a single phrase, what would you say?

JPL: His true insight was that there is an inseparable and organic connection, between individuals and their social circumstances, that is the source of thinking. This connection, in mainstream psychology and linguistics, including SLA, has in many ways been severed, resulting in a dichotomized psychology, much in the way the language under Saussure's influence was dichotomized-separated from its speakers.

JJ: How has your thinking on Vygotsky evolved since you first entered the field?

JPL: Vera John-Steiner once said to me that reading Vygotsky was like traveling through a long tunnel. Only after being in the tunnel for years and years can one begin to see the light at its end. This is precisely what my experience of Vygotsky has been. When one first reads Vygotsky, one thinks it is understandable, almost a common sense way of thinking about the connection between mind and society. But until you read between the lines and realize that what Vygotsky was proposing was a profound new ontology of what it means to be human, you don't really understand his 
work. If you were to look at my set of his collected writings you would see evidence of my different readings of him in what is underlined and what is commented on in the marginalia.

This is a long-winded way of getting to my answer-the single most important notion to be discovered in Vygotsky is his dialectical perspective on human consciousness. Until this notion emerges in your thinking, you are left with a collection of concepts (the ZPD, private speech, mediation, activity, sense, meaning, etc.).

SLA is still functioning under a set of dichotomies that I think have prevented us from fully understanding the nature of language learning and teaching. These include competence/performance, learning/acquisition, input/output, learning/use, individual/social, explicit/implicit knowledge, teaching/assessment, teacher-centered/learner-centered pedagogy, et cetera. At the moment I am carrying out what is likely to be an extended project on what SLA would look like from a dialectical rather than a dichotic perspective.

JJ: Could you unpack the term dialectical? How does it differ from contextual or interrelated? If something is done in dialogue, does that make it dialectical?

JPL: To function dialectically means to be able to hold in one cognitive space notions that on the surface appear to be contrary (learning/development, implicit/explicit knowledge, input/output, etc.) and to come to understand how these seeming contraries fit together as necessary components of the object of study.

Dialogue and context are events and spaces. What matters is the quality of what happens in these events and spaces. A dialogue for instance can be antagonistic rather than dialectical. A dialogue can also be cooperative and even collaborative without being dialectical.

A dialectical view of the world, going back to Spinoza, for instance, understands the world as inherently integrated, including especially events and activities that on the surface appear to be contrary. The dichotic/dualistic viewpoint breaks this natural nexus whereby the whole is shattered and with it the very nature of what one is trying to understand and or participate in. So, to argue for the independence of learning and development, as is done in a classic Piagetian perspective, loses sight of the possibility that learning and development are components of a unity: one builds upon the other in a potentially unending cycle. The same can be said about the relationship between the individual and the social, learning and assessment, et cetera. 
The dialectic is at the heart of what we know as human society. The reason people hang together in societies is because we are different from each other and therefore we need and rely on each other. If we were all the same, there would be no society.

James Lantolf is to speak at the upcoming Independent Learning Association's conference Exploring Theory, Enhancing Practice: Autonomy across the Disciplines, to be held October 5-8, 2007, at Kanda University of International Studies in Chiba, where he will give a plenary address on the topic "Autonomy and Sociocultural Theory."

\section{References}

Lantolf, J. P. (2000). Sociocultural theory and second language learning. Oxford: Oxford University Press.

Lantolf, J. P., \& Appel, G. (1994). Vygotskian approaches to second language research. Norwood, NJ: Ablex Press.

Lantolf, J. P. \& Thorne, S. L. (2006). Sociocultural theory and the genesis of second language development. Oxford: Oxford University Press.

\section{Additional Reading}

Frawley, W., \& Lantolf, J. P. (1985). L2 discourse: A Vygotskyan perspective. Applied Linguistics, 6, 19-44.

Frawley, W., \& Lantolf, J. P. (1984). Speaking and self-order: A critique of orthodox L2 research. Studies in Second Language Acquisition, 6, 143-159.

John-Steiner, V. (1997). Notebooks of the mind: Explorations of thinking. (Rev. ed.). New York: Oxford University Press.

John-Steiner, V. (2000). Creative collaboration. New York: Oxford University Press. Lantolf, J. P., \& Frawley, W. (1985). Oral proficiency testing: A critical analysis. The Modern Language Journal, 69, 337-345. 